\title{
Commentary: Addiction as an adaptation process in the brain, a view from neurobiology
}

\author{
Esa R. Korpi \\ Department of Pharmacology, Faculty of Medicine, University of Helsinki, Finland
}

\begin{abstract}
Research on the brain mechanisms of dependence on alcohol and drugs of abuse has rapidly advanced during the last two decades. We know the main processes, especially how the drugs are acting on their targets on brain cells, but this basic knowledge has not been well translated to better therapies. Not surprisingly, neurobiological addiction research is tackling the same fundamental questions as all neuropsychiatric research. For example, what are the roles of individual neuronal populations in different phases of addiction (development, maintenance, craving and compulsion, abstinence and relapse)? For preclinical research, novel neurogenetic methods now show great promise to answer at least some of the questions, but more innovative work is required to build models and find mechanisms for social and environmental interactions in addiction and to translate the inventions to clinical therapies. Addiction as a disease concept still gives a proper framework for this line of important research.
\end{abstract}

The term "addiction" is often used in medical writings. Just typing the word in the search field of the PubMed database generates over 40,000 references to the term, the first one dating back to more than 100 years ago (1914). This enormous usage of the term makes one feel humble, although everybody knows that the word/concept has been/is used in various meanings at different times and by different scientists and politicians.

Neurobiology describes drug addiction as a persistent adaptation process to repeated (voluntary) consumption of addictive substances (Figure 1). Therefore, neurobiology can conveniently dissect the process of addiction into subcomponents to be more precisely studied separately. The well-known problem in biomedical sciences on animal models of human diseases is that the experiments that would be most relevant to human conditions lack the precision, especially at the brain cellular and molecular levels (except perhaps for genetic polymorphisms). For example, activation of various brain circuits and neurons can be monitored precisely in neurobiological models, but human brain imaging systems allows only brain regional measurements. Thus, if neurobiology would only study the addicted human brain, we would know very little how the drugs are working and how the brain is adapting to their repeated presence and withdrawal. We would also know little of the mechanisms of how drug consumption develops into habits and compulsive behavior. Since addiction has been related to the fundamental processes of the brain, such as learning and memory, the research in recent years has detailed the mechanisms of many addictive drugs in regulating the addiction-related pathways of the rodent brain (Kauer \& Malenka, 2007; Luscher \& Ungless, 2006).

One important aspect in brain research and biology in general has been the understanding that there are redundant processes that operate at neuronal circuitry and molecular levels. For example, alcohol-related behavioral effects and chronic abuse-related behaviors can be explained by multiple primary molecular actions of small hydrophilic ethanol molecules that are distributed throughout the body water space (Spanagel, 2009). Alcohol can relieve anxiety in rodent models by enhancing inhibitory GABA mechanisms, by reducing excitatory glutamate mechanisms, or by enhancing neuropeptide mechanisms, such as neuropeptide Y (NPY) and opioid peptides, with each component also showing a strong effect alone. Maybe these different processes can at some point be effectively related to subtypes of alcoholism? What we know much more poorly is how the voluntary self-administration (oral or operant intravenous consumption) is transformed into compulsive drug taking, but the current evidence suggests that there must also be multiple pathways into compulsion and relapse (Everitt \& Robbins, 2005).

Why is the term addiction beneficial for biomedical scientists? There are two points that I want to make here. First, the addiction field as its own entity is a way of separating a small "discipline" for the scientists that are interested in understanding the disease of addiction and making a genuine effort in solving scientific questions related to the field. Second, as a respected separate field of

Correspondence: Esa R. Korpi, MD, PhD, Department of Pharmacology, Faculty of Medicine, P.O. Box 63 (Haartmaninkatu 8), FI-00014 University of Helsinki, Finland. Telephone: +358 2941 25330, FAX: +358 2941 25364, E-mail: esa.korpi(at)helsinki.fi 
Figure 1

Flow chart of the mechanisms of drug addiction, based on concepts nowadays accepted in pharmacology textbooks.

\section{Mechanisms and phases of drug addiction}

Repeated and wanted dosing of drugs of abuse (exposure)

Pharmacological actions at
eceptors
Environment
Development
Learning and memory
Conditioning
Stress, withdrawal
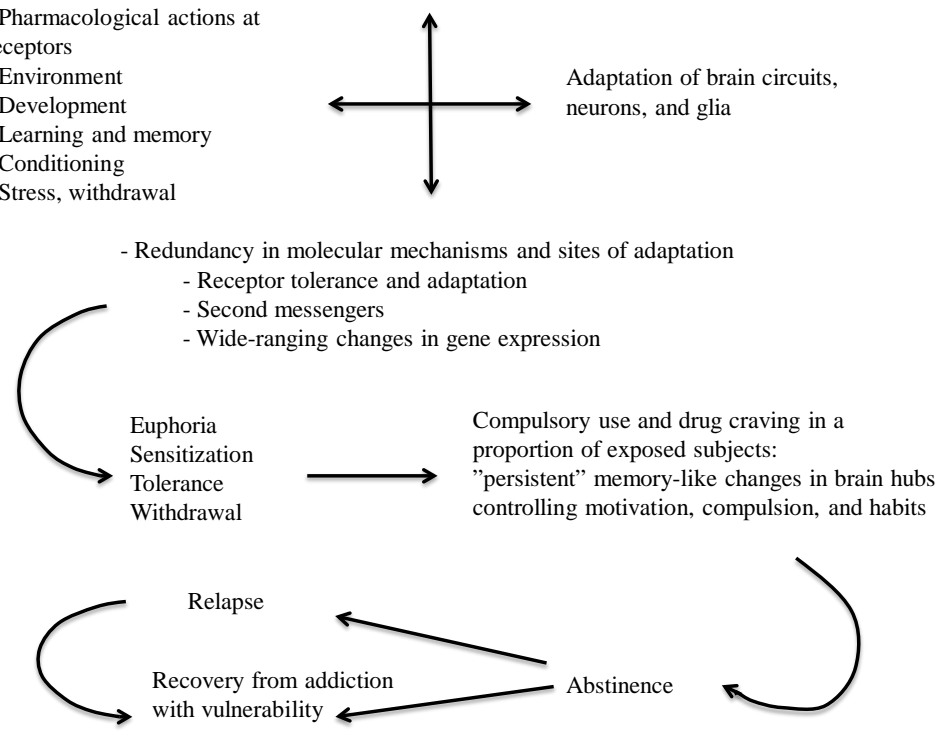

science, the funding most likely is better than if all biomedical addiction research would be distributed to parts of pharmacology, toxicology, neuroscience, or psychiatry. On the other hand, it has to be admitted that any advancement in the addiction field is based strongly on the general advancement of biomedical and biological sciences in methodology and concepts.

Emerging new concepts and results from selective modulation of single neuronal populations and from functional and molecular modulation of synaptic memory processes are two promising new areas of neurobiological addiction research. For example, we can regulate reward/ aversion by selective activation/inactivation of midbrain dopamine neurons or inhibitory GABA neurons (Adamantidis et al., 2011; Tan et al., 2012; van Zessen, Phillips, Budygin, \& Stuber, 2012) using novel optogenetic or pharmacogenetic tools that have given for the first time the possibility to modulate brain activity at a single neuronal population level. These new methods are based on genetic modification of specific neuronal populations, often using viral vectors in the transfer of light or drugsensitive ion channels/receptors that can be activated later to stimulate or inhibit neuronal firing without disturbing the basic functions of the brain (Deisseroth \& Schnitzer, 2013; Wulff et al., 2007). While this kind of detailed basic neurobiological research is still out of reach in human addiction research, more selective tools are also emerging for human research and treatment. It is interesting that an old method of brain electrical stimulation is intensively studied at present, fine-tuned and tried for the treatment of alcohol addiction (Heinze et al., 2009; Kuhn et al., 2011;
Pierce \& Vassoler, 2013), based on basic research and on human brain imaging research. A very specific kind of reward pathway activation has been shown to induce remarkable reduction in alcohol drinking of rats (Bass et al., 2013), suggesting that modulation of neuronal activity in the addicted brain in a minor but very precise fashion can have efficacy. So, goal-directed and habitual behaviors can be modulated. But again, these novel tools and ideas are useful not only for addiction research but are also relevant to most other neuropsychiatric illnesses, such as depression and anxiety.

Memory traces are thought to be permanent in a healthy brain. However, recent exciting findings of erasure of memory traces by a selective antagonist of the protein kinase M zeta (Li et al., 2011; Sacktor, 2011; Shema, Sacktor, \& Dudai, 2007) have increased the hope that permanently established neuronal connections could be reorganized later in life. Although these results have been questioned (Lisman, 2011; Volk, Bachman, Johnson, Yu, \& Huganir, 2013; Wu-Zhang, Schramm, Nabavi, Malinow, \& Newton, 2012), indicating that we do not understand the molecular mechanisms well enough, this line of research might turn out to be very fruitful for the future understanding of the memory-like processes that make compulsive addiction so persistent. How do "addicted" synapses differ from other synapses? Are they located differently in neurons or do they contain proteins or other molecules that could be selectively targeted for inactivation during the treatment process? Can these synapses be programmed in early development by adverse life events, 
and once identified can they be inactivated by specific therapies?

Synaptic strength is modulated by neuronal activity and drugs of abuse (Citri \& Malenka, 2008), which can be mimicked by optogenetic methods at desired neuronal populations. So, certain kinds of neurostimulation can activate and strengthen synaptic connections, while another kind can depress and weaken them (Nabavi et al., 2014). Could we highjack the compulsive motivational processes harnessed by addictive drugs back to motivational tasks for non-addictive behaviors? Basic research has suggested that once these processes are activated by one drug, the effects of other drugs or other rewarding stimuli are occluded (Borgland, Malenka, \& Bonci, 2004; Chen et al., 2008; Wise \& Koob, 2014), suggesting that there is a ceiling effect in how much neuroplasticity, neurodegeneration, and brain modulation various drugs can induce.

Let us hope that it does not take another 100 years before we know how to self-prevent the development of addiction to harmful substances and habits and before physicians know how to effectively cure the addicted patient once some kind of compulsive addictive behavior has emerged. In the meantime, the addiction concept will inevitably be revised, transformed, or renamed as relevant processes are better established in the human brain to orchestrate emotional, motivational, and behavioral options within a native environment.

\section{References}

Adamantidis, A. R., Tsai, H. C., Boutrel, B., Zhang, F., Stuber, G. D., Budygin, E. A., . . . de Lecea, L. (2011). Optogenetic interrogation of dopaminergic modulation of the multiple phases of reward-seeking behavior. Journal of Neuroscience, 31(30), 10829-10835. doi:10.1523/JNEUROSCI.2246-11.2011

Bass, C. E., Grinevich, V. P., Gioia, D., Day-Brown, J. D., Bonin, K. D., Stuber, G. D., . . . Budygin, E. A. (2013). Optogenetic stimulation of VTA dopamine neurons reveals that tonic but not phasic patterns of dopamine transmission reduce ethanol selfadministration. Frontiers in Behavioral Neuroscience, 7, 173. doi:10.3389/fnbeh.2013.00173

Borgland, S. L., Malenka, R. C., \& Bonci, A. (2004). Acute and chronic cocaine-induced potentiation of synaptic strength in the ventral tegmental area: Electrophysiological and behavioral correlates in individual rats. Journal of Neuroscience, 24(34), 7482-7490. doi:10.1523/JNEUROSCI.1312-04.2004

Chen, B. T., Bowers, M. S., Martin, M., Hopf, F. W., Guillory, A. M., Carelli, R. M., . . Bonci, A. (2008). Cocaine but not natural reward self-administration nor passive cocaine infusion produces persistent LTP in the VTA. Neuron, 59(2), 288-297. doi:10.1016/j. neuron.2008.05.024

Citri, A., \& Malenka, R. C. (2008). Synaptic plasticity: Multiple forms, functions, and mechanisms. Neuropsychopharmacology, 33(1), 18-41. doi: 10.1038/sj.npp.1301559
Deisseroth, K., \& Schnitzer, M. J. (2013). Engineering approaches to illuminating brain structure and dynamics. Neuron, 80(3), 568-577. doi: 10.1016/j. neuron.2013.10.032

Everitt, B. J., \& Robbins, T. W. (2005). Neural systems of reinforcement for drug addiction: From actions to habits to compulsion. Nature Neuroscience, 8(11), 1481-1489. doi:10.1038/nn1579

Heinze, H. J., Heldmann, M., Voges, J., Hinrichs, H., Marco-Pallares, J., Hopf, J. M., . . . Munte, T. F. (2009). Counteracting incentive sensitization in severe alcohol dependence using deep brain stimulation of the nucleus accumbens: Clinical and basic science aspects. Frontiers in Human Neuroscience, 3, 22. doi:10.3389/neuro.09.022.2009

Kauer, J. A., \& Malenka, R. C. (2007). Synaptic plasticity and addiction. Nature Reviews Neuroscience, 8(11), 844-858. doi:10.1038/nrn2234

Kuhn, J., Grundler, T. O., Bauer, R., Huff, W., Fischer, A. G., Lenartz, D., . . S Sturm, V. (2011). Successful deep brain stimulation of the nucleus accumbens in severe alcohol dependence is associated with changed performance monitoring. Addiction Biology, 16(4), 620-623. doi:10.1111/j.1369-1600.2011.00337.x

Li, Y. Q., Xue, Y. X., He, Y. Y., Li, F. Q., Xue, L. F., Xu, C. M., . . . Lu, L. (2011). Inhibition of PKMzeta in nucleus accumbens core abolishes long-term drug reward memory. Journal of Neuroscience, 31(14), 5436-5446. doi: 10.1523/JNEUROSCI.5884-10.2011

Lisman, J. (2012). Memory erasure by very high concentrations of ZIP may not be due to PKM-zeta. Hippocampus, (22)3, 648-649. doi:10.1002/hipo. 20980

Luscher, C., \& Ungless, M. A. (2006). The mechanistic classification of addictive drugs. Public Library of Science Medicine, 3(11), e437. doi:10.1371/journal. pmed.0030437

Nabavi, S., Fox, R., Proulx, C. D., Lin, J. Y., Tsien, R. Y., \& Malinow, R. (2014). Engineering a memory with LTD and LTP. Nature, 511(7509), 348-352. doi:10.1038/nature13294

Pierce, R. C., \& Vassoler, F. M. (2013). Deep brain stimulation for the treatment of addiction: Basic and clinical studies and potential mechanisms of action. Psychopharmacology (Berl), 229(3), 487-491. doi:10.1007/s00213-013-3214-6

Sacktor, T. C. (2011). How does PKMzeta maintain longterm memory? Nature Reviews Neuroscience, 12(1), 9-15. doi:10.1038/nrn2949

Shema, R., Sacktor, T. C., \& Dudai, Y. (2007). Rapid erasure of long-term memory associations in the cortex by an inhibitor of PKM zeta. Science, 317(5840), 951-953. doi:10.1126/science.1144334

Spanagel, R. (2009). Alcoholism: a systems approach from molecular physiology to addictive behavior. Physiological Reviews, 89(2), 649-705. doi:10.1152/ physrev.00013.2008

Tan, K. R., Yvon, C., Turiault, M., Mirzabekov, J. J., Doehner, J., Labouebe, G., . . . Luscher, C. (2012). GABA neurons of the VTA drive conditioned place aversion. Neuron, 73(6), 1173-1183. doi:10.1016/j. neuron.2012.02.015 
van Zessen, R., Phillips, J. L., Budygin, E. A., \& Stuber, G. D. (2012). Activation of VTA GABA neurons disrupts reward consumption. Neuron, 73(6), 1184-1194. doi:10.1016/j.neuron.2012.02.016

Volk, L. J., Bachman, J. L., Johnson, R., Yu, Y., \& Huganir, R. L. (2013). PKM-zeta is not required for hippocampal synaptic plasticity, learning and memory. Nature, 493(7432), 420-423. doi:10.1038/ nature 11802

Wise, R. A., \& Koob, G. F. (2014). The development and maintenance of drug addiction. Neuropsychopharmacology, 39(2), 254-262. doi: 10.1038/npp.2013.261

Wu-Zhang, A. X., Schramm, C. L., Nabavi, S., Malinow, R., \& Newton, A. C. (2012). Cellular pharmacology of protein kinase Mzeta (PKMzeta) contrasts with its in vitro profile: Implications for PKMzeta as a mediator of memory. Journal of Biological Chemistry, 287(16), 12879-12885. doi: 10.1074/jbc.M112.357244

Wulff, P., Goetz, T., Leppa, E., Linden, A. M., Renzi, M., Swinny, J. D., . . . Wisden, W. (2007). From synapse to behavior: Rapid modulation of defined neuronal types with engineered $\mathrm{GABA}_{\mathrm{A}}$ receptors. Nature Neuroscience, 10(7), 923-929. doi:10.1038/nn1927 